\title{
REGIÓN Y GLOBALIZACIÓN: EL PROBLEMA DE LA IDENTIDAD
}

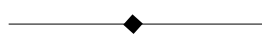

\section{RESU M E N}

En estedocumento se presenta una reflexión sobrela relación queseestableceentre región, globalización e identidad. Partiendo de una interpretación en cuanto a identidad se refiere, el objetivo aquí, es mostrar queel proceso de globalización en tanto dominante, no tiendea desaparecer a la región, antes bien, la reafirma. Procesos financieros y productivos sostenidos a través de los lineamientos de la libre competencia aparecen como elementos quevan a caracterizar más profundamente el proceso deregionalización. En lo queal caso denuestro territorio hace, la frontera nortees un ejemplo claro delo quela región representa en el proceso deglobalización. Laidentidad regional no subyacea la globalización, la frontera norteasí lo manifiesta, los procesos laboral es y la cercanía con el país más poderoso del mundo representa una enorme ventaja para los intereses del capital privado transnacional quellegan a establecer sus empresas a lo largo de la frontera norte. Así pues, el norte del país seenfunda en una identidad especial a partir deexigencias globalizantes. Es entonces quela región y la globalización aparecen en estedocumento como un problema de la identidad (o de identidades si se requiere).

\section{ABSTRACT}

Region, globalization and identity are the central elements in this document. To starting the interpretation of identity, I shows that the globalization process, even though is the dominant process, doesn 't make desappear the region, but it reaffirm it. Financial and productive processes sustained through the limits of the free competition appear as the elements that will characterize the regionalism process more deeply. The north frontier is a clear example of what the region represents in theglobalization process. Theregional identity doesn't underlieto theglobalization, thenorth frontier, thelabor processes and its proximity to themost powerful country of theworld represents an enormous advantage for theinterests of thetransnational enterprises when somecompanies establ ishing its along thenorth frontier. Therefore, the region and the globalization appear as a problem of theidentity (or of identities if it is required in this document).

\footnotetext{
* Maestría en Ciencias Sociales Aplicadas, instituto de investigaciones SocialesUnIVERSIDAD AUTÓN OMA DE BAJA CALIFORNIA. Correo electrónico: balbuena@faro.ens.uabc.mx
} 


\section{INTRODUCCIÓN}

Para el desarrollo de este ensayo partiremos de una pregunta importante, ¿cuál es la relación que podríamos encontrar en los siguientes tres supuestos: región, globalización e identidad? La hipótesisqueaquí sugerimos nos permiteapostar queexisteuna amplia y profunda relación entre identidad, región y globalización. En este sentido, se sostendrá que el proceso de globalización, contrariamente a lo que pudiera suponerse, no destruye la identidad regional, sino que actúa sobre ella y supone una afirmación dela identidad frentea la visión totalitaria.

Esimportante, por tanto, poner en claro lo siguiente: Una identidad puedeser vista teóricamente desdediferentes ópticas. A bordar el tema desde el punto de vista social significa entablar una dialéctica con un sinnúmero de el ementos convergentes que edifican una identidad. Sin embargo, nos encontraríamos en un riesgo latente, puesto que esta tarea únicamentenos llevaría a la constitución deuna identidad social, por lo tanto particular, y a su vez delimitada en su propia erección y justificación. En estesentido, laconstitución deunaidentidad ideológica respondería mejor a los entramados de los procesos históricos y económicos que dan sentido a una identidad regional y nos permite contextualizarla dentro delos procesos deglobal ización.

Esto nos lleva al planteamiento del objetivo en este ensayo y que apuntaremos inicialmente como interrogante: En el contexto de la globalización, ¿qué pasa con las regiones?

Bajo esta perspectiva, la identidad nos permitirá explicar algunos procesos relacionados con la regional ización y la globalización, como elemento central dediscusión.

Sin embargo, hablar sobre identidad nos lleva a otra pregunta esencial que tendremos que responder antes de entrar de lleno al análisis del regional ismo en la globalización: ¿Cómo seconstituyeuna identidad?Y demanera más precisa, ¿cómo seconstruyeuna identidad en el plano ideológico?

Es así como iniciaremos con algunos postulados básicos que nos ayudarán a comprender este proceso mediante el cual se construye una identidad en el plano ideológico. Sin embargo, cómo seinstituyeo 
se "institucionaliza" una identidad es un proceso interesante que merece un análisis aparte, por lo que no nos ocuparemos de ello en este escrito. Aquí solamentellegaremos hasta lo que es el proceso de "edificación" identitaria, paraluego analizar su presenciay su relación con los procesos de regionalización y su participación en el contexto delaglobalización.

En este sentido, las proposiciones provenientes del análisis antropológico o sociológico solamente se ocupan de la identidad "constituida" bajo parámetros culturales y comportamientos cotidianos que giran o se explican en relación con el mundo de las expectativas sujetales. A demás, tienen lugar más en el mundo delas interacciones sociales que en las simbólicas. Esto nos llevaría a considerar un plano de acción de las identidades muy reducido y no se referiría a la construcción simbólica-ideológica quenos interesa sobresaltar en este ejercicio. Es decir, estaríamos hablando de una identidad social (en las colectividades), y no de una "identidad económica" (como modelo). Aquí es fundamental aclarar que estos dos "tipos" de identidades no son exclusivas o excluyentes la una dela otra, al contrario, puedellegar un punto - como veremos-en el queambas parecen complementarse. Aún más, la identidad desde este punto de vista propone una visión solamente en el ámbito social pero no explica los fundamentos sobre los cuales se "amarra" la identidad.

En resumen, y particularizando más el objetivo: es el proceso ideológico el que emite los parámetros sobre los cuales se crea una identidad y se "materializa" mediante un "sincronismo" discursivo; es decir, la identidad, al tiempo que se crea en lo "inmaterial", se constituye en lo "material", a través de lo que Zizek (1992) denomina el "acolchado discursivo".

En ese aspecto es significativo apoyarnos en proposiciones provenientes del psicoanálisis clásico, en la proposición lacaniana de la identidad y el significante o point de capiton sobre el cual se sostiene parte fundamental del ensayo. Pero también será significativo partir de una de las más interesantes proposiciones sobre identidad provenientes del interaccionismo simbólico que nos permitirá ver la relación entrela identidad social y laidentidad ideológica: la propuesta deErving Goffman (1968), en su obra titulada Estigma. La identidad deteriorada. 
Una vez establecido el problema de la identidad, lo siguiente es realizar al gunas reflexiones sobre el comportamiento de la identidad regional en el contexto gl obal. Final mente, seel abora un breveanálisis sobre la identidad de la región norte del país. Así pues, el objetivo fundamental de este escrito es reparar un poco sobre dos cosas: 1) analizar el comportamiento regional en un contexto global, y 2) analizar el comportamiento de la identidad regional en la zona norte del país en su relación hacia el exterior y hacia el interior.

\section{SOBRE LA IDENTIDAD}

Sobre la construcción de una identidad podríamos recurrir a explicaciones o posiciones/ propuestas provenientes dela sociología o la antropología, pero por situaciones a las queya hemos hecho al usión, lo más pertinente es comenzar con las proposiciones lacanianas en la interpretación deZizek.

Parece ser que los "dilemas" de la identidad en el contexto de la globalización tienden a la recurrencia en un sól o sentido: la dualidad: nacionalismo e identidad; Estado e identidad; sujetos e identidad, etcétera. Los niveles sobre los cuales se "mueve" el concepto mismo representa la facultad de la ubicuidad y la transgresión. Sin embargo, el binomio identidad... " $n$ ", presenta siempre una complementación entre la totalidad y la otredad; la exclusión y la inclusión. De igual forma, toda manifestación identitaria guarda también especial relación con un "centro" emisor encargado de estructurar y dotar de "personalidad" a la identidad. La identidad no podría explicarse a sí misma sin la edificación-constitución de un núcleo capaz deelaborarreelaborar códigos simbólicos y culturales; es decir, un núcleo específicamente organizador y "dotador" de sentido a la unión de las convergencias mediantelas cuales se "formal iza" la identidad.

Si entendemos que socialmente somos resultado de una serie de acciones y relaciones específicas, entonces el mundo en el que nos desarrollamos y relacionamos no resulta ser más que una construcción simbólico-social. En este sentido, todo lo que podemos y hemos realizado como sujetos, es una estructuración entre lo simbólico y lo social. Y esta estructuración da sentido a una realidad quenos capacita 
y nos dota de una identidad social virtual . ${ }^{1}$ Es, en esa identidad social virtual, donde se fundamenta y se concretan las diferencias y los estigmas. La proposición de Goffman a este respecto es muy simple. Cuand o habla sobrela concepción-constitución deesta identidad social virtual puedeconducirnos a una discusión ontológica: si cada uno de los individuos, por sí solos, presentan características personales particulares (y en donde estas particularidades conforman una identidad social-virtual), esta identidad a la que Goffman se refiere solamenteestá respondiendo a un contexto social quepuedeexplicar perfectamentesu acontecer en el mismo espacio de lo público y, por lo tanto, responder a una multiplicidad de objetivos especiales y propios del mismo plano, sin embargo, no respondería de la misma forma en el plano de lo ideológico. Incluso, parecería que en esa identidad social, bastarían al gunas variaciones en los planes deacción para quetal identidad comenzara a experimentar cambiosy, tal vez, experimentar, como consecuencia, su fragmentación (de esta forma es como pueden entenderse aquellas identidades que se formulan a partir de ciertas condiciones partidistas). De esta manera, lo que tendríamos es una convergencia de ciertas particularidades en donde seconcreta una posibilidad deidentidad; es decir, dela constitución de una identidad social.

Sin embargo, esto no está del todo al ejado de nuestra intención de encontrar la forma en cómo se construye la identidad en el plano ideológico, por lo menos en la convergencia de las particularidades. En estepunto hay quecentrar nuestra atención sobreesa convergencia.

\footnotetext{
${ }^{1}$ Recurrimos a las proposiciones que Goffman realiza sobre esta concepción en la que, según el autor, existeuna identidad social virtual que seva formando en tanto existen ciertas atribuciones de características especiales sobre los individuos. Es decir, éstos - Ios individuos - secaracterizan detal forma queadquieren una especie de estatus especial y específico, lo que les diferencia entre sí y transfiere el carácter de unicidad pero que, sin embargo, no refleja la verdadera naturaleza del propio sujeto. De esta forma se percibe la diferencia sobre los sujetos individuales y se forma la identidad social virtual.
} 
Regresando un poco al interaccionismo simbólico, lo que Goffman proponees quemásallá dela atribución o imputación decaracterísticas específicas que se hacen sobre el sujeto, se encuentran aquellos otros atributos que, "según pueden demostrarse", le pertenecen al individuo propiamente, esto es, la identidad social real. Ambas, identidad social virtual e identidad social real, son constitutivas de una "identidad" superior quesubsumea las dos anteriores. Aquí seencuentra el punto interesanteen la constitución identitaria y queseresumeen la siguiente pregunta: ¿Cómo se logra estructurar esta diversidad de atributos y características específicas para conformar un todo más estructurado y/ o más complejizado? Más claramente: ¿Cómo sesignifica así misma una identidad?

Es imposible, en este sentido, escapar al sentido ideológico que, finalmente, no sólo constituye a una identidad sino que la valida, le brinda especificidad y "funcional idad", la justifica.

Antes hablábamos sobre el mundo social como resultado de una estructura entrelo simbólico y lo social. ${ }^{2} \mathrm{Si}$ seda por sentado que existe una clara diferenciación entreambos espacios, podemos contextualizar el proceso de constitución identitaria en un mundo simbólico, y esto nos dota de grandes posibilidades para comenzar a respondernos la pregunta esencial en esteapartado: ¿Cómo secrea una identidad en el plano ideológico?

Zizek dice que existe un "plano" en el cual una identidad secrea y se sostiene sobre un "cúmulo de significantes flotantes". Éstos son elementos que se encuentran "flotando" en un espacio o dimensión querebasan la tangibilidad. En tanto protoideológicos, esecúmulo de significantes permanecealejado del mundo real-concreto, por lo tanto, son intangibles, inal canzables e irrealizables. Sin embargo, el cúmulo puedey tiendea la convergencia en tanto existeun elemento capaz de

${ }^{2}$ A quí entiendo a "Io social" como el espacio en quereproducimos comportamientos específicos "cotidianos" que guardan un carácter de especificidad-generalidad y que permiten la individualidad al tiempo que generan la colectividad. 
significarlesy, a la vez, proporcionarles la justificación queles dota de sentido. Esto es a lo que Zizek Ilama "el punto nodal" o "point de capition" lacaniano: "el cúmulo designificantes flotantes, deelementos protoideológicos, se estructura en un campo unificado mediante la intervención de un determinado punto nodal (el point de capition Iacaniano) que los acolcha, detiene su deslizamiento y fija su significado" (Zizek, 1992:125).

Aquí lo importante es no perder de vista un elemento básico: el point de capition quesirve de "acolchado", puesto que es a partir deél queseestructura el proceso explicativo y desentido en la construcción ideológica dela identidad en Zizek.

De esta forma, pues, una identidad va más allá de la pura y simple convergencia de características especiales, incluso de un conjunto de atribuciones especiales. La identidad seexplica por la existencia de un "significante padre", de un point de capition capaz de significar a todo un conjunto de significados "inespecíficos" y girar, así, hacia la especificidad identitaria.

En este sentido, tendríamos que una identidad —más allá de la "aglutinación" derasgos específicos como el color depiel, la orientación sexual, los procesos económicos, empresariales o los relacionados con "Io nacional" - dotaría de sentido a las especificidades en tanto lo simbólico provee un peso especial a la acción de las colectividades. Esto explicaría, de alguna forma, la constitución de las "pluridentidades", como los acontecimientos de 1968, las manifestaciones homosexuales masculinas y femeninas e, incluso, las alianzas partidistas.

Expliquemos un poco más: el acolchado de Zizek sobre el cual se "significan los significantes", no es aquel inherente a una atribución especialmente "concreta", antes bien al contrario, es la característica "significativa" que organiza y justifica a la "unidad" identitaria. El acolchado, por ejemplo, en la lógica del sistema de producción capital ista, no es otra cosa que el capitalismo propio. En términos de Zizek, es "aquello queestá en el objeto más queel objeto mismo", y en ese sentido el acolchado en este caso, dota de sentido al significante capital ista al tiempo que otorga otro "sentido" al significante obrero. Éstos, a su vez, únicamenteforman concepciones propias en el marco 
del acolchado del capital ismo. Final mente, esteacolchad o forma parte de otro que le desborda.

Sin embargo, parece que lo esencial del acolchado es que no sólo dota de sentido a los significantes sino que, al tiempo que es capaz de esta "transferencia", permite constituir una identidad empresarial y una identidad obrera; éstos, en función de otro significante padre, instituyen una identidad capital ista.

Como resultado y siguiendo a Zizek, la identidad no sería una construcción "concreta". La identidad se funda en la "inconcretud" ideológica, en el mundo delo significante, en el espacio delo simbólico.

A hora bien, en un mismo contexto como el dela globalización, ¿cómo se manifiesta una relación entre points de capition diferentes? Es decir, ¿cómo secomportan lasidentidades?

Antes deavanzar, convendría hacer una última reflexión sobreuna cuestión que es importante analizar: ¿Cómo se "concretiza" lo "inconcretizable"? Deforma mássimple ¿Cómo logra manifestarseuna identidad?

Según Zizek, existe un "plus" ${ }^{3}$ mediante el cual aquello que es simbólico determina la configuración "funcional" delaidentidad. Este plus no es otra cosa que las formas discursivas mediante las cuales la identidad toma sentido y se dirige a la concretud de las acciones. De estaforma, el discurso es el el emento capaz deconectar al mismo tiempo el campo ideológico (de la identidad) y el mundo de lo real-concreto. Deesta forma, existiría una retroacción entrelo significantey lo concreto capaz detraducirse en una identidad específica, en la identidad misma.

Ejemplificando los postulados deZizek, la lógica capitalista funciona bajo un postulado básico: la propiedad privada, y, en este sentido, el pensamiento-discurso sobre "productividad" esindispensablepara el éxito empresarial y para la sobrevivencia obrera. Sin embargo, el

${ }^{3}$ Zizek utiliza este término para referirse a un espacio de lo simbólico que, sin embargo, provee la facultad de trasladar los significantes hacia el significado. Es decir, dota de sentido a lo simbólico. 
"espectro" empresarial sól o sesignifica bajo los parámetros específicos provenientes del discurso de productividad-hegemonía y sobre las relaciones depoder. La segmentación y saturación delos mercados de consumo, la transformación de losmodel os de producción (fundamentalmente a nivel obrero-patronal) y las grandes organizaciones, entretejen una nueva unión y una dimensión compleja de relaciones económicas. Las reestructuraciones en los espacios laborales y la división espacial del trabajo advierten el resque-brajamiento de los límites territoriales económicos sobre lo que posteriormente se va a sostener el sistema de redes contemporáneo ${ }^{4}$ que actualmente predomina en la economía mundial (Gaudemar, 1979). Aquí, la jerarquía aparecería como una concentración de flujos informativos, como una policomputación (Morín, 1988) capaz de cubrir todas las posibilidades deproducción, incluidaslaorganización, estructuraciones y reestructuraciones del espacio físico y delas diferentes dimensiones de la vida social: trabajo, cultura, etcétera.

\section{SOBRE LA IDENTIDAD Y EL ACONTECER HISTÓRICO-ECONÓMICO}

Podemos decir, en términos escuetos, queel proceso de gl obalización se presenta ante nosotros como el "ambiente" en el cual la evolución política, científica, tecnológica y económica, prácticamente han transformado el sentido del espacio, de la frontera y dela movilidad. Es decir, desde un punto de vista muy particular, ha dotado de capacidad transformadora a todo nuestro concreto-real, en donde la capacidad deutilización (diversificación) tecnológica sepresenta como el elemento espeć́fico sobreel cual la información fluctúa detal manera que "agiliza” los procesos de comunicación, por lo tanto, también los de decisión, así como los deorganización. Bajo estas condiciones sería prudente preguntarnos: ¿Qué ha pasado con las regiones?

${ }^{4}$ Wai Chung (1994) señala que las organizaciones entretejen redes de información que, a su vez, son el sustento del éxito empresarial en el contexto dela globalización. 
Por otrolado, pareceser queuna vez quelas fluctuaciones decapitales y las mercancías rebasan el modelo geográfico de movilidad terrestre marítimo-aéreo, en el medio delas relaciones productivas y comerciales se presenta el epifenómeno de la información. De esta forma, y como bien señala Bordieu (1991), "Io que estaba al ejado se acerca”.

Duranteel esplendor de la circulación delas mercancías por las vías terrestres o marítimas (léase mercantilismo), las grandes distancias presentaban tanto ventajas como ciertas dificul tades queentorpecían el intercambio. Las ventajas, por supuesto, sepueden explicar medianteel propio proceso deintercambio: la creación degrandescentros queemiten estilos de vida, de servicios y de infraestructura que caracterizan a las ciudades comerciales. Por otro ladoy al mismo tiempo, seconformaban rutas específicas de comercio a ultramar que permitían el intercambio entre regiones y, en este sentido, la especificidad sobre la "necesidad" deestablecer fronteras respondía a dos cuestiones básicas:

Por un lado, a la construcción deuna identidad nacional y, por el otro, a una construcción identitaria empresarial-comercial. De hecho, lo que Smith (tal vez inintencionalmente) estaba haciendo con su Riqueza de las $N$ aciones, era iniciar la constitución de una identidad nación: si la riqueza no provienepropiamentedel campo sino, por el contrario, del intercambio comercial, entonces habría que sentar las bases propias para lograr el "entarimado" ideológico quesostendríatal proposición identitaria. De esta forma, el plus metafórico se articula en torno a las condiciones de existencia propias de la época; es decir, el discurso se elabora y tiene sentido en tanto existe una clase de "emprendedores" con intereses u objetivos específicos que van más al lá de la simple acumulación.

En este sentido, la "riqueza de una nación" funciona como el uno lacaniano capaz designificar los procesos simbólicos; es decir, orientarlos en la consecución específica del objeto-deseo: la riqueza misma.

Los procesos deindustrial ización se muestran al mundo como una ambigüedad5 utilitaria en los procesos productivos que, por sobreotras

${ }^{5}$ Quizá sería más pertinente referirnos a una ambivalencia más que a una ambigüedad, sin embargo, cuando Marx señala que la máquina terminará por sustituir al ser humano, meparecequeponedemanifiesto la imprecisión conceptual dela función de la maquinaria, en ese sentido, me parece el carácter ambigüo. 
cosas, agiliza y divideel trabajo en la esfera dela producción. En este contexto, las observaciones marxistas identifican el proceso del desarrollo capitalista como una determinación del devenir histórico quetendrá que culminar con su propia desaparición en la emergencia del comunismo. Marx percibe el proceso de trabajo como aquél que encarna en sí mismo la producción del excedente que escapa a la posesión del productor directo; deestaforma, el remanenteproveniente del proceso productivo es una delas condiciones básicas del capitalismo al igual que la propiedad privada y la circularidad de la tierra. Así, Marx percibe claramente que la plusvalía y la renta no son estáticos, sino que permanecen variables en el desarrollo histórico.

Por otro lado, sobre las bases teóricas del marxismo, Lenin explica la necesidad de "un enormeejército deobreros" funcionales a losfines objetivos de la lógica capital ista.

Es más que significativo que este enorme ejército de obreros presentaran más similitudes que diferencias en sus estilos devida: las manifestaciones obreras y los despidos masivos estructuran y direccionan los estilos de vida hacia la consolidación dela colectividad, la cual, irónicamente, debe su existencia a una dialéctica proveniente de una estructura jerárquica totalmente polarizada. A quí la concentración del poder permiteno sólo el control sobrelos medios de producción, sino que, al entretejerseen las relaciones sociales, domina también la vida cotidiana.

En otro sentido, los grandes avances del industrialismo, las grandes producciones (extensivas), poco a poco van delineando las nuevas formas de producción-intercambio. El avance de los sistemas de intercambio da un gran sal to con la transportación aérea.

Así, mientras el Estado nación partía dela constitución deterritorios específicos y espacial es capaces de responder a las reglas dela oferta y la demanda para incrementar su riqueza, los progresos industriales ciertamente reforzaban esos territorios pero tendían también a agotarlos. Por ello, no es accidental que después dela segunda guerra mundial se produzca una apertura delas economías, sobretodo delas llamadas de primer mundo. Pero, al mismo tiempo, se generaron grandes procesos productivos que, a su vez, generan un elemento distintivo que ha de permanecer cada vez con mayor fuerza en los 
procesos históricos económicos: competencia-productividad-diversidad, que a su vez, responderá a otra determinación del sistema capitalista: la fragmentación de los mercados.

\section{¿Y LASREGIONES?}

Aquí, volvemos a retomar la pregunta que dejamos pendiente: ¿Qué pasa con las regiones? Mejor aún: ¿Qué pasa con la identidad-región en la globalización?

Como señala Anderson (1997), una frontera es lo que representa y es constantemente modificada por el propio proceder humano, que también lo influencia, delimita y define. Esta definición pareceacertada, sobre todo si aceptamos que los regionalismos se encuentran delimitados geográficamente. De ahí la pertinencia de hablar sobre regiones económicas, además de quelos propios episodios históricoseconómicos han agotado o han permitido que el horizonte sobre las determinaciones territoriales pierdan validez, puesto que los intercambios - que a su vez han experimentado una evolución de lo mercantil a lo informacional - tienden a disminuir las del imitaciones geográficas regionales. Es decir, bajo el contexto dela globalización, la región pierde cierta delimitación, sin embargo, esto no le permite escapar a sus determinaciones territoriales.

De hecho, lo quela globalización significa es lo quela posesión de la información permite, y en este aspecto, el poder también se transforma; es decir, el poder también muestra diversidad y adaptabilidad, por lo que: el poder ya no es entendido como un "oligopolio territorial". En el plano dela gl obalización, el poder (objeto-deseo inalcanzable) es accesible en tanto esa accesi bilidad se adscribe, fundamentalmente, a los avances informáticos-computacionales, y así, la diada poderinformación puede funcionar como un bucle recursivo: informaciónpoder.

Así, el discurso (plus metafórico) tendrá que ser capaz ya no de lo significativo, pues el plus metafórico ya no es uno solo en un contexto en el quela información permitela diversificación, sino queformaliza los lineamientos del poder y permite la interacción entre diferentes cotos de poder. De esta forma, el uno lacaniano puede ser al mismo 
tiempo compatible con otros unos lacanianos, puesto que "Io característico de los el ementos global izados [...] es queestán separados de una organización social particular [...] esta separación de las redes y las colectividades... hace que sólo vivamos juntos en la medida en que hacemos los mismos gestos y utilizamos los mismos objetos" (Touraine, 1997:9). Esto, por supuesto, no se aleja mucho de la "sospecha" marxista sobrela alienación del ser humano. Sin embargo, la característica del contexto contemporáneo estriba en el reconocimiento hacia las particularidades y las independencias, que pueden ser autorreconocidas en tanto son capaces de agruparse hacia "Ia gran significancia" de "lo particular". A hí se enfrenta a la generalidad a la vez que la complementa dejando entrever esa separación de redes y colectividades. Así, la identidad regional se presenta como el gran paradigma de la contemporaneidad, como la gran contradicción del sistema global. Esto nos Ilevaría a la paradoja quetitula el siguiente apartado.

\section{¿HAN DESAPARECIDO LASIDENTIDADESREGIONALES?}

Hemos visto que el plus metafórico es el elemento central que materializa el mundo significante de una identidad. De esta forma podemos, sin mayores pretensiones, observar que las distintas fases económicas históricas tienden a edificar y fortal ecer esteplus metafórico que amalgama una ideología específica sobre las bases sujetales, así, Marx realmente "edifica" una identidad obrero-empresarial en una concepción del propio capital ismo sobreuna base discursiva específica.

"Obreros del mundo uníos" es la consecución de una construcción identitaria global; es una construcción de innumerables expresiones identitarias sobre regiones económicas específicas que les dota de individualidad al mismo tiempo queles transfiereindependencia. Sin embargo, las identidades regionales no se forman a través de un discurso emitido por lasfuerzas económicas del propio sistema, sino por las "unidades" queconforman todo el sistema productivo. Puesto que la ideología provenientedel discurso deestas "unidades" suponeladiferencia de estilos particulares, también nos habla de regionalismos específicos. Al mismo tiempo, supone una pertenencia, un sentido de 
inclusión a unarealidad queseclarifica a partir de un significantepadre: lo regional.

Por último, la identidad regional cobra mayor sentido en un contexto de diversidad productiva y de formas específicas de competencia. De esta manera, el discurso proveniente del proceso de globalización (sustentado en conceptos como diversidad, información y productividad) no produce la desaparición de los regionalismos sino, al contrario, los dispensay los reafirma. En el mismo sentido en queafirma una inclusión en los lineamientos de los procesos productivos, también promueve la "individualidad" - no sólo subjetiva sino regional - de identidades específicas. Es el horizonte trazado mediante la productividad por medio del cual las regiones secrean y seconfirman gracias al ciclo: competencia-productividad-diversidad, creando otro más específico y quesustenta no sólo la actuación de la región sino de la globalización misma: información-poder-inclusión al proceso mundial productivo-decisión-resultado.

Así pues, la identidad regional funciona como un "órgano" interno que brinda mayor funcionalidad a las implicaciones productivas del sistema mundial capitalista (uno lacaniano). Es sobre la misma lógica sobre la que descansa la identidad sujetal (exclusión) y colectiva (inclusión) de la región en un contexto de globalización en donde la distribución de actividades ya no puede ser sustentada en las propiedades territoriales, y solamentepuedeser entendida en términos decostos detransacción y productividad. Deahí queel discurso sobre productividad seorientehacia la maximización derecursos sobreuna baseideológica quepromueveuna identidad competitiva y asimétrica ${ }^{6}$

\footnotetext{
${ }^{6}$ En una recientedeclaración, el presidentedel consejo deadministración del Grupo Financiero Banorte (La Jornada, 11 de noviembre de 1999:16), evidencia los lineamientos sobre eficientización y los criterios de calidad sobre los cuales la inclusión de la economía mexicana en el proceso de globalización puede ser sustentado: “Los procesos deintegración [...] también exigen mantener la disciplina económica y ser suficientemente innovadores para adquirir ventajas competitivas, permitir un crecimiento sostenido y dar al país estabilidad económica [...] El reto para los mexicanos, frente a la globalización, es no perder identidad y soberanía nacionales". Es importanteseñalar cómo el propio discurso permiteuna asociación
} 
nacional, global o regional. En este sentido, el discurso toma validez en tanto supone las expectativas de las dlases dominantes poseedoras delainformación necesaria para intervenir en las decisiones económicas mundiales. Sin embargo, puesto que la accesibilidad a la información es relativamente amplia, quienes acceden a ella no forman ya centros de poder específicos, sino que estructuran "redes" de relaciones que proporcionan poder (Wai Chung, 1994). De esta forma, pertenecer a ella significa mayor accesibilidad a lainformación y, como consecuencia, al poder. Así, mientras que la integración regional se sustenta en la posesión y uso dela información misma, la diferenciación regional se explica mediantela lógica de productividad gl obalizadora. Como diría un lema de internet: "Piense gl obal pero actúe local".

Así, pues, la identidad regional actúa en dos sentidos estrictamente distintos pero no estrictamente excluyentes: un espacio para sí y un espacio en sí. Es decir, una identidad regional que actúa en relación con sí misma (a intereses y expectativas propias) y una identidad en si, sobre la que actúan "fuerzas" exógenas. En este entendido, la globalización no ha eliminado la región, la ha fortificado, aunque ello represente, como he dicho antes, una contradicción en la que, como bien se ha preguntado Touraine: ¿Podremos vivir juntos?

Sin embargo, antes de proseguir en la discusión, es importante realizar una reflexión sobre aquello que hasta aquí ha permanecido como un hecho inherente al análisis pero sobre lo que no se ha particularizado: la importancia del espacio y la identidad en la conformación deuna región.

\section{EL ESPACIO Y LA IDENTIDAD EN LA CONFORMACIÓN REGIONAL}

Claval (1982) sostienequela vida social está directamenterelacionada o por lo menos seriamenteinfluenciada por el espacio o territorialidad; eso nos lleva a suponer que existe una relación dialéctica entre el

casi "delictuosa" entrecompetitividad, crecimiento y estabilidad en la construcción de una identidad "globalizadora" que, sin embargo, se diferencia muy bien de una identidad nacional. 
desarrollo dela vida social y el espacio en queéstasegenera: "el espacio interviene de diversas maneras en la vida social [...] 1) Es el sostén de la vida y de la actividad einterviene entonces por la extensión; 2) Es obstáculo para la vida de relación; 3) Sirve de base a la actividad simbólica.

En tanto espacio, el territorio7 seerige como la localización específica de la vida social, al mismo tiempo que media las acciones; es decir, sirve de mediación entre las diferentes acciones sociales.

En otras palabras, las expresiones humanas únicamente pueden crear vínculos en tanto se sujetan a una territorialidad específica que les brinda ciertas comodidades: a) permitela emergencia de vínculos de afectividades; b) permitela constitución de sistemas estructurados de comunicación y difusión de informaciones; c) genera elementos identitarios medianteuna articulación deprocesos, formasy relaciones deproducción.

El espacio es capaz deerigirsecomo el lugar en dondelas relaciones sociales toman coherenciay sereferencian a partir deuna delimitación del propio espacio. Lo quees importantenotar, es queexisteun sentido de la estructuración no sólo del espacio, sino de la vida en general percibida solamente a través dela identidad regional.

Por otro lado, la estructura espacial puedeser generadora de cierto fenómeno o "temporalidad específica": constituye una condición material deexistencia. "Así, los diversos el ementos dela vida cotidiana tan sólo se imponen si consiguen organizar gestos y significados en torno al uso de un espacio" (Remy y Voye, 1976:41).

El espacio se constituye entonces, sustento material a la vez que espacio de socialización, generación de procesos productivos y movimientos financieros específicos. De esta forma, se extiende una conciencia degrupo que no sereduce solamenteal compartimento de un espacio común (regional), sino a la propia estructura resultado del

7 Para una explicación más profunda sobre la relación conceptual de espacio, territorio y frontera véase Arturo Ranfla (1984:47-68). 
comportamiento entre la composición social y espacio, que se tejen y entretejen en la medida en que la propia estructura espacial y las técnicas decomunicación sevan complejizando.

Los procesos evolutivos económicos y sociales y los procesos evolutivos del espacio aparecen como capacidades potenciales continuas capaces de generar, a su vez, formaciones socioeconómicas particulares o regionales.

Por otro lado, la circulación de informaciones - caracterizadas ya como un sistema demercancías o productos queinteractúan con y bajo las condiciones del mercado mundial y las políticas regionales-, el flujo de capitales, las empresas transnacionales y la transformación del Estado, son algunos el ementos quemodifican las relaciones con la espacialidad einciden directamenteen la conformación dela identidad regional.

Así, el anál isisespacial del territorio regional es importanteen tanto sintetiza las capacidades dearticulación entre sujetos, sistema político, procesos productivos, cultura, etcétera, con el espacio; sintetiza la composición de la identidad regional y se constituye, a la vez, como eseuno lacaniano capaz dedotar desentido a la espacialidad identitaria.

La globalización, por su parte, presenta una particularidad que tiende a la generalización y a la particularización; a la igualdad, al tiempo que a la diferenciación. En ese sentido, los cambios en la producción (en donde los límites se establecen en relación con la demanda y no a la oferta) son generadores de un reordenamiento territorial, en donde la frontera pierdeespecificidad y el regionalismo identitario tiende a reafirmarse.

La identidad regional surge así como una consecuencia específica de ese proceso que "lo globaliza todo" y que amplía la división del trabajo a escalas mundiales en pos dela maximización delos beneficios. Pero, además, responde a un fin utilitario de los sistemas de mercado y que Touraine denomina "espíritu mercantil", en donde todas las formas identitarias, más al lá de su representatividad, son funcionales a la lógica de una región en un contexto de globalidad.

Deesta forma, no resultailógico pensar queuna región secaracterice, fundamentalmente, medianteelementos productivosy, en eseaspecto, la localización, el espacio mismo, cobra especial importancia: “el caso 
de Monterrey donde 'la industria es creadora de una organización regional 'resulta [...] excepcional y también seconsiderala importancia de las industrias maquiladoras de la franja fronteriza mexicana" (Bassols, 1988:32).

En estesentido, la región no es solamenteun producto del desarrol lo histórico delas relaciones deproducción y poder, sino también deuna capacidad generadora desímbolos unificantes quejustifican procesos particulares relacionados con la economía y la producción y el espacio capaces de dar sentido y forma a una identidad regional: Monterrey, como ciudad industrial, explica esa relación entre el discurso que manifiesta la "excepcionalidad" sostenida en una localización especial, a la vez queen procesos productivos particulares y en la aplicación de tecnología industrial.

Aquí el carácter de "lo productivo" reviste gran importancia. En tanto el proceso de globalización ha sido capaz de disgregar y complejizar los procesos productivos, ha establecido el sentido de la especialización. Así, podemos encontrarnos de frente con ese carácter contradictorio entre la generalización (de lo global y lo nacional) y la diferenciación o particularización (de la regionalización), del "saber hacer" delos procesos productivos.

Finalmente, la región aquí no sirveúnicamente como mero pretexto en la construcción identitaria, sino que supone una relación estrecha entre las diferentes variables económicas y el sentido de identidad establecido entre sociedad y espacio, ese espacio en el que se generan hábitosy pautas culturales, y dondelas acciones setornan acciones de sentido: productividad, competencia y eficiencia regional.

Sin embargo, el espacio regional se supone más que como una localización sociopolítica, como un área económica de sentido que se orienta hacia una función "asignada" por el sistema mundial capitalista. Sobreesa "asignación" las regiones se conforman diferencial menteen un territorio cualquiera afirmando su identidad y en donde la localización es fundamental para su inclusión o exclusión en el juego del mercado internacional, en los procesos globalizantes de las economías modernas. En estas condiciones, la frontera nortede México juega un papel esencial en la economía nacional. 


\section{LA FRONTERA NORTE DE MÉXICO}

"El norte", "el centro", "el sur". ¿A quéresponden estas diferenciaciones en el territorio nacional? ¿A quérespondeesta regionalización? Es una buena pregunta, quesin embargo no podemos responder dela mejor manera sino a modo de suponer que corresponde a dos cosas importantes para esteanálisis: a una funcionalidad espacial y económica -en el sentido de una mejor administración delos recursos basada en la innovación tecnológica aplicada a la industria-, y a una necesidad de identidad específica que facilite y/ o posibilite su distinción en la inclusión-diferenciación de la globalización. En cierto sentido, esto tiene que ver con la instauración o creación de polos económicos o polarización que supone algunas cosas que hay que poner de manifiesto.

Por un lado, un polo hegemónico suponela generación, emisión y “distribución" deformas dedesarrollo (Dela Garza, 1992:3-9), además de constituirse como el eje sobre el cual giran las más importantes decisiones sobre las pol íticas económicas. Por otro lado, suponeademás un núcleo constituido a través de la macroempresa de exportación transnacional y, citando de nuevo a De la Garza, también de la participación del capital privado nacional.

Bajo estas condiciones, la región se distinguiría por contener en sí misma estas características. Deesta forma, una región puedeser capaz de constituir polos hegemónicos (macrocefálicos) que emiten las políticas económicas mediante las cuales se rigen las acciones y estrategias macro gracias a la composición basada en la producción de exportación transnacional: el Distrito Federal, Monterrey, etcétera.

En este sentido, las aspiraciones regionalistas son todo menos imprecisas o indefinidas. Tienen que concretarse categórica y vigorosamente en reivindicaciones específicas de producción y bienestar geográfico-regional. Sobre estas bases, el regionalismo no puede ser la expresión vaga de un malestar y de un descontento siemprey cuando la planeación política sea la adecuada. Igualmente, esta planeación estaría dirigida -en teoría por lo menos- a establecer una equidad y una integración de las zonas más pobres al contexto de "lo nacional". 
Bajo estas premisas, hablemos ahora sobre la región norte del país, su constitución identitaria y los procesos deintegración-distinción entre lo nacional y lo global.

Básicamente, el fenómeno de la reestructuración y modernización industrial y tecnológica comenzó en nuestro país hacia los inicios dela década de los ochenta y se manifestó con gran fuerza en la zona de la frontera norte (Carrillo y dela O, 1992:54-59) en la industria maquiladora. A quí, las transformaciones parten desdelas estructuras más bajas hasta niveles empresariales; sin embargo, preguntémonos algo determinante ¿A quéresponde real menteesta reestructuración?

Por un lado, tenemos un desplazamiento de la economía mundial del lado de la oferta (productor) hacia una economía de consumo (demanda). Por el otro lado, un cambio en los intercambiosmercantiles - avanzando de la circulación de productos terminados hacia la circulación deproductosintermedios-acompañado detransacciones predominantemente financieras, creando así una relación entre mercado demercancías por una parte, y mercados de capitales por la otra, con exigencias sobre una homologación de políticas económicas nacionales-globales. ${ }^{8} \mathrm{~A}$ sí, los procesos de "liberación económica" permiten una acumulación de capitales a escala mundial y, además, dotan de "un sentido" deubicuidad al mundo empresarial, deahí que las grandes transacciones financieras predominen actualmente(Huerta, 1999:98-100).

Esto muestra que el proceso de globalización se presenta con un sino de integración más fuerte que a su vez incide en las transformaciones delos modos deorganización productivo-social. Los efectos de integración regional seexplican a partir deestos procesos dela economía mundial y delos requerimientos internacionales. México no puedeser

${ }^{8}$ En el caso de la frontera norte, este proceso puede apreciarse en la industria maquiladora de autopartes para la exportación. El artículo de Jorge Carrillo (1987) ejemplifica no solamente el proceso de la reconversión de la industria automotriz sino los cambios en la esfera de la circulación de mercancías en un contexto de globalización. 
la excepción. La región de la frontera norte se constituye bajo estos supuestos económicos que lo totalizan todo, lo generalizan, lo globalizan.

La identidad de la región norte responde también a los mismos lineamientos provenientes de las exigencias de la producción gl obal. Teóricamente, los conceptos como "cultura laboral" y "flexibilidad" forman parte de una estructura discursiva que pretende erigir una identidad laboral sobrela cual los procesos productivos alcancen niveles de eficiencia tales que el juego internacional de producción no le trasciendan. Al parecer, la importancia fundamental sobre la cual se crea una identidad desde el plano ideológico y en un contexto económico, competitivo y diverso, radica precisamenteen la lucha por la vigencia de las economías nacional es en el mundo moderno.

A hora bien, ¿por quées tan importantela identidad en estecontexto? Dado que la identidad no es otra cosa más que la convergencia de puntos perdidos en lo simbólico significados por un point de capition capaz de dar sentido a esa convergencia y acolcharlos hacia la materialidad medianteel plus metafórico, éstatienela virtud detraducir las "significancias" en comportamientos, antes dispersos y generalizados, en una actitud. La concreción de la identidad a través del discurso emanado de los lineamientos simbólicos-económicos provenientes delas exigencias económicas internacionales, le proveen de un sentido utilitario conveniente al sistema de producción globalizador. Esto es, la identidad regional toma sentido en tanto no sólo respondea la lógica de producción global, sino queinteractúa con la misma. Asimismo, seinstituye como parteinherentedel discurso de "Io nacional". En este sentido, el acolchado funge como la capacidadposibilidad deinteracción entrelo gl obal y lo regional-nacional.

El discurso laboral y su redefinición actúan bajo los lineamientos de los mercados diferenciados y tienden a la creación de un sector formal fragmentado percibido através dela intervención de un reducido grupo de empresas, en este caso, fronterizas. En tal sentido, la identidad laboral-regional respondemása estas "imposiciones" delibremercado y de competencia internacional, que a su vez se "embona" hacia el interior medianteuna constelación depequeñas y medianas empresas con producción orientadaal mercado interno. 
La identidad regional fronteriza en el nortetiende, pues, a responder a los lineamientos de la economía global sin que por ello pierda identidad frenteal sinnúmero deidentidades que componen el mundo significante de la globalidad misma. Aunque el discurso proveniente de la lógica capitalista moderna tienda a ser el acolchado mediante el cual todas las "significancias" seidentifican, las formas de estediscurso son perfectamente diferenciadas en contextos distintos. El acolchado "regional" fija una serie de características específicas que "emiten diferencias" percibidas por otras identidades regionales. Al mismo tiempo que el plus metafórico concretiza una identidad regional fronteriza, "el norte" se sitúa en un nivel de diferencia en sentido concreto: niveles de desempleo, niveles de ingreso, seguridad social, prestaciones, productividad, etcétera. Pero sobre todo, una industria sólida con grandes potenciales de producción y adaptabilidad a las fluctuaciones productivas internacionales.

Por otro lado, las condiciones de estabilidad o inestabilidad social también son elementos que permiten el establecimiento delos grandes capitales transnacionales en nuestro país. De ahí que no nos resulte extraña la austeridad empresarial-industrial en la frontera sur del país, en donde los conflictos sociales proporcionan un ambiente inestable, por lo menos para los intereses empresariales-industriales. Quizás esto sea una de las bondades territoriales sobre la cual los geógrafos contemporáneos ponen mayor atención. En este sentido, la cercanía con el país "más poderoso del mundo" representa una enormeventaja para los intereses del capital privado transnacional que llegan a establecer sus empresas a lo largo de la frontera norte. Esto nos lleva a pensar que es el espacio mismo el que genera lugares estratégicos de comercio quepermiten el florecimiento delaindustria empresarial como tal (la historia puededotarnos degran cantidad deejemplos sobreeste punto).

La interdependencia en la economía mundial, las corporaciones transnacionales y sus estrategias económicas en un entorno de competencia internacional, han contribuido de la mejor forma a la ubicación y/ o generación de espacios estratégicos que aseguren la permanencia y redituabilidad financiera. Así pues, el norte del país se enfunda en una identidad especial a partir de estas exigencias 
globalizantes. La población de zonas áridas y/ o con grandes necesidades que dificultan la producción de cultivo pero que, estratégicamente, proporcionan la infraestructura básica de servicios, han logrado desarrollar una identidad también particular. El sentido de lo regional, en el norte, se sustenta en "el reto" de florecer donde parecía imposible hacerlo, bajo condiciones adversas y por "esfuerzo propio". Sin embargo, ¿cómo entender la identidad dela región norte sin la contextualización territorial?

La cercanía con los Estados Unidos de N orteamérica no solamente ha representado ventajas, ${ }^{9}$ sino queha "complementado" la identidad fronteriza del norte. La ubicación territorial, en esesentido, permitela materialidad dela identidad, la concreción, la sujeción a una serie de prácticas particulares y específicas.

De esta forma tenemos, por un lado, toda una práctica discursiva sustentada en las "disposiciones" dela global ización y, por otro lado, una representación dela real idad concreta queconforma una "realidad" o visión del mundo específica sobrela cual las unidades económicas se interrelacionan. De esta forma, la identidad emprende una relación recursiva entre "la otredad" (lo exterior) y alter (el interior), que se significan únicamente en el objeto-deseo imposible, ${ }^{10}$ es decir, en la constitución de una identidad diferenciada hacia el exterior pero igual itaria al interior; esto significa quela identidad regional del norte seestructuramedianteuna renovación constantequepermiteorientarse y reorientarse de manera funcional hacia dos postulados básicos que hemos tratado deseguir a lo largo de esteensayo: lo internacional y lo nacional. Y hacia abajo, dándonos un poco de libertad y si hablamos en sentido de estructura horizontal, lo regional y lo nacional.

${ }^{9}$ El Banco de Información Económica del INEGI, para el año 2000 reporta que los Estados Unidos de Norteamérica es el país que invierte mayor capital en nuestro país. Gran parte deesas inversiones sequedan directamenteen la franja fronteriza, en estados como Baja California y Nuevo León.

${ }^{10}$ Imposible en tanto es el objeto de construcción sobre el cual se sustentan las acciones y sobre el cual giran todas las expectativas. Es el objeto inacabado, inalcanzado en tanto la dinámica de las interacciones sociales van renovando constantemente las atribuciones de éste. 
Así pues, la construcción de una identidad en el plano ideológico pareceser más funcional y apropiada a las conveniencias del proceso de globalización, más aún que aquellas identidades sociales que, no menosimportantes, susmanifestaciones pueden ser únicamente reflejo deeventos particulares políticos, económicos, culturales, etcétera y que responden más bien al plano de las subjetividades y no al nivel de análisis de unidades económicas regionales en el contexto de la globalización; opone menos resistencia al análisis pero también al mismo sistema.

\section{CONCLUSIONES}

¿Cómo se plantea en la actualidad la cuestión del regionalismo? La existencia de un sentimiento regional ista es al go innegableen nuestros días. No podemos pasar por al to las premisas productivas sobre las cuales se estructura la pertenencia regionalista: Florida y su especialización en jugos; Idaho en su producción de papas; Detroit y su producción automovilística; Silicon Vall ey en computación, etcétera.

Aquí parece ser que la discusión sobre el regionalismo sufre un desplazamiento del plano económico y social hacia un contexto más integrador sobre lo social y lo económico-político. Esto, necesariamente, Ileva hacia una reconsideración sobre el papel y la función de las regiones en el contexto mundial, quetambién sedesplaza delo nacional hacia lo global y, consecuentemente, delas economías nacionales a las economíasglobales.

Las consideraciones sobre identidad y región no son algo novedoso como tampoco lo es queel proceso deglobalización, lejos de desaparecer el regional ismo, lo confirme, lo conforme como una identidad especial más funcional a las exigencias de dos cosas que también se complementan: el propio sistema globalizador y la constitución delo nacional.

Las innovaciones tecnológicas aplicadas a la economía mundial, presentan una gama de identidades suvbertidas, a su vez, en una constelación de identidades: la teledetección, los sistemas de comunicación y cibernéticos, han desplazado las barreras territoriales y políticas al tiempo que han modificado profundamente el mundo productivo, mercantil y decapitales. 
El hecho de que las unidades económicas vivan un "mundo de sentido", implica la competencia misma en cuanto al dominio de las prácticas. En este aspecto, la identidad regional se sobreescribe a sí misma; es decir, dado queel sentido del mundo económico ha sufrido transformaciones claras mediante las innovaciones tecnológicas aplicadas a la producción, el "nuevo sentido" permite también la competencia y la conformación de/ entre "otras" identidades requeridas para el "nuevo orden" mundial, pero también reafirma el papel funcional delaidentidad regional económica (esto también implicaun cambio tanto en la posesión como en la ejecución del poder).

De esta forma, la identidad regional en el norte del país presenta sus propias estructuras conformadas y modificadas medianteaspectos particulares como las exigencias globalizantes (de "nuevo sentido") y las experiencias propias a la interacción entrelas unidades y el espacio.

Es en la industria de la maquiladora deexportación (IME) en donde los primeros procesos demodernización seperci ben con cierta agudeza. Laincorporación denuevas tecnologías, la reestructuración en la gestión de recursos humanos y en la organización de los espacios físicos y contractual es de la esfera laboral, son un indicador de las exigencias planteadas por el sistema global de producción y por las condiciones dela competencia internacional.

Por otro lado, las prácticas corporativas comerciales y lainternacionalización productiva constituyen, poco a poco, un sistema de redes específico sobre el cual actualmente giran las grandes decisiones económicas a nivel mundial.

Sobre estas bases, la evolución de la industria maquiladora puede ser entendida en dos ejes fundamentales. Por un lado, presenta una evolución tanto en número como en la estructura productivalaboral y física, pasando de plantas concentradas en actividades de ensamble sencillo de componentes aisladas, a un número más grande de maquiladoras: más de 2000 plantasen toda la franja fronteriza en 1991. Esto también supone una capitalización considerable de equipo y maquinaria. La administración productiva bajo lineamientos como el "justo a tiempo", "cero inventario" y "control decalidad”, han dotado a la empresa maquiladora de capacidad suficiente para la producción deartículos con al tas especificaciones. 
Esta práctica discursiva ${ }^{11}$ es la que conforma la identidad misma, la dota de funcionalidad, de diferencialidad, pero también marca el sentido delainclusión-exclusión.

La oscuridad del juego entablado por el proceso de globalización radica aquí. Los puntos oscuros son aquellos que parecen contradictorios entresí pero que, al mismo tiempo, son altamente complementarios. La inclusión, que es el sentido depertenencia a "algo", permite la integración a un proyecto denación queda sentido ala misma región, pero es también el ancla que permitela sujeción haciala territorialidad misma. Mientras tanto, la exclusión revierte el proceso y excluye "aquello" que no tiene pertenencia a "esto", que no presenta sujeción a la territorialidad. La instalación de empresas transnacionales en la frontera norte del país cumpleperfectamenteel requisito deintegración (el uso de mano de obra local, la generación decierto nivel deempleo, etcétera), pero al mismo tiempo están expuestas a la exclusión y, en consecuencia, a la no identidad regional. Sin embargo, la red de relaciones que establecen a su alrededor, después de todo, es lo que amal gama la identidad económica regional en el contexto de la globalización contemporánea, la reafirma y la renueva.

${ }^{11}$ Que no es el término simplista sobre la expresión oral de las ideas o la ejecución proveniente del sistema mismo (y que la mayor de las veces en la cotidianeidad pueden ser o son entendidas como una seriededisposiciones o imposiciones), sino una consideración hacia la integración tanto deelementos propiamentediscursivos como acciones específicas. 


\section{BIBLIOGRAFÍA}

Bassols, M. (comp.) et al . (1988). A ntología de sociología urbana. UNAM. Bordieu, Jean (1991). El sentido práctico. Taurus, México.

Carrillo, Jorge(1987). “La reconversión en laindustria del automóvil”, en: El cotidiano, edición especial, núm. 1.

Carrillo y De la O. (1992). "La reestructuración en la industria maquiladora", en: El cotidiano, núm. 46, marzo-abril.

Claval, Paul (1982). Espacio y poder. FCE, México.

Dela Garza Toledo (1992). “La polarización del aparato productivo en México", en: El cotidiano, núm. 46, marzo-abril.

Gangster, Sweedler, Scott y Dieter-eberwein (1997). Borders and Border

Regions in Europeand N orth A merica, Institutefor Regional Studies of the Californias, San Diego, California.

Gaudemar, J.P. (1979). M ovilidad del trabajo y acumulación decapital, Era, México.

Goffman, Erving (1968). Estigma. La identidad deteriorada. A morrortu Editores, Buenos Aires.

González y Castellanos (1999). “La globalización demanda cambios políticos, señala González Barrera", en: La jornada, 11 de noviembre.

Huerta, Arturo (1999). "La globalización como causante de la crisis económica actual”, en: Problemas del desarrollo, Revista Latinoamericana de Economía, núm. 117, vol. 30, abril-junio.

Jacobs, J. (1999). Cities and theweal th of nations principles of economic life, VintageBooks, EUA.

Morín, Edgar (1988). El M étodo, vol. III, Cátedra, Madrid, España. Ranfla, Arturo (1984). "Frontera política y espacio fronterizo”, en: revista Estudios fronterizos, núms. 4-5, mayo-agosto/ septiembrediciembre, Mexicali, B.C.

Remy y Voyé (1976). "La escuela de Chicago", en: La ciudad y la urbanización, IEAL, España.

“Espacio y estructura”, en: La ciudad y la urbanización, EIAL, España.

Touraine, Alan (1997). ¿ Podremos vivir juntos? La discusión pendiente: EI destino del hombre en la aldea global, FCE, M éxico. 
Wai Chung, Y.H. (1994). “Critical review of Geographical Perspectives on Business Organization of Productions: Towards a Network A pproach", en: Progress in H uman Geography, vol.18, núm. 14. Zizek, Slavoj (1992). El sublime objeto de la ideología, Siglo XXI, México. 